\title{
Predictors for benign paroxysmal positional vertigo with positive Dix-Hallpike test
}

This article was published in the following Dove Press journal:

International Journal of General Medicine

| December 201 |

Number of times this article has been viewed

\section{Kazutaka Noda \\ Masatomi Ikusaka \\ Yoshiyuki Ohira \\ Toshihiko Takada \\ Tomoko Tsukamoto \\ Department of General Medicine, \\ Chiba University Hospital, \\ Chiba, Japan}

Correspondence: Kazutaka Noda Department of General Medicine,

Chiba University Hospital, I-8-I Inohana,

Chuo-ku, Chiba-shi,

Chiba 260-8670, Japan

Tel/fax +8I 432244758

Email nodakazutaka@graduate.chiba-u.jp
Objective: Patient medical history is important for making a diagnosis of causes of dizziness, but there have been no studies on the diagnostic value of individual items in the history. This study was performed to identify and validate useful questions for suspecting a diagnosis of benign paroxysmal positional vertigo (BPPV).

Methods: Construction and validation of a disease prediction model was performed at the outpatient clinic in the Department of General Medicine of Chiba University Hospital. Patients with dizziness were enrolled (145 patients for construction of the disease prediction model and 61 patients for its validation). This study targeted BPPV of the posterior semicircular canals only with a positive Dix-Hallpike test (DHT + BPPV) to avoid diagnostic ambiguity. Binomial logistic regression analysis was performed to identify the items that were useful for diagnosis or exclusion of DHT + BPPV.

Results: Twelve patients from the derivation set and six patients from the validation set had DHT + BPPV. Binomial logistic regression analysis selected a "duration of dizziness $\leq 15$ seconds" and "onset when turning over in bed" as independent predictors of DHT + BPPV with an odds ratio (95\% confidence interval) of $4.36(1.18-16.19)$ and 10.17 (2.49-41.63), respectively. Affirmative answers to both questions yielded a likelihood ratio of $6.81(5.11-9.10)$ for diagnosis of DHT + BPPV, while negative answers to both had a likelihood ratio of $0.19(0.08-0.47)$.

Conclusion: A "duration of dizziness $\leq 15$ seconds" and "onset when turning over in bed" were the two most important questions among various historical features of BPPV.

Keywords: benign paroxysmal positional vertigo, likelihood ratio, diagnosis, screening, prediction rules

\section{Introduction}

Patient medical history is considered to be important for making a diagnosis of causes of dizziness (rotational or nonrotational), which is a common complaint in general practice. ${ }^{1,2}$ This is because a wide variety of diseases can cause dizziness and objective findings are often lacking on physical examination or when tests are performed.

Benign paroxysmal positional vertigo (BPPV) is the most common type of dizziness in general practice..$^{3-8}$ Although BPPV can affect each of the three semicircular canals, the majority of BPPV cases are of the posterior canal, and anterior canal involvement is exceedingly rare. Posterior canal BPPV has been said to account for $60 \%-90 \%$ of all BPPV cases, and horizontal canal BPPV for 5\%-30\% of the cases. ${ }^{9-14}$ Therefore, this study focused on posterior canal BPPV. Important features of medical history in patients with BPPV include the onset of vertigo due to a change of head position 
and a duration of $\leq 1$ minute. ${ }^{15,16}$ To establish a diagnosis of posterior canal BPPV, characteristic nystagmus should be confirmed by the Dix-Hallpike test and this is one of the diagnostic criteria. ${ }^{16}$ However, in the real-life clinical setting, characteristic nystagmus often cannot be detected by the Dix-Hallpike test in patients with a history suggesting BPPV of the posterior canals. It has been reported that a certain subset of patients may not demonstrate the typical nystagmus during the Dix-Hallpike test, which has been termed "subjective" BPPV, and it accounts for about one-fourth of patients with suspicious BPPV. ${ }^{13,17,18}$ If dizzy patients likely to have BPPV and a positive Dix-Hallpike test (which allows a definite diagnosis of BPPV of the posterior canals) could be identified at an early stage while taking a medical history, it would make diagnosis of causes of dizziness more efficient. However, a search of the literature found no relevant studies.

Accordingly, this study was performed to identify the most useful information from medical history for predicting a diagnosis of BPPV with a positive Dix-Hallpike test $($ DHT + BPPV $)$.

\section{Methods}

This study included outpatients who presented to the Department of General Medicine of Chiba University Hospital (hereafter "the department") with the chief complaint of dizziness from July 2005 to May 2007 (the derivation set). Based on a search of the literature, questions were selections that were considered to be important for making a differential diagnosis of dizziness and interview sheets were prepared. The questions covered the mode of presentation and duration of dizziness, the features of dizziness (rotational or nonrotational), causative movements, accessory symptoms such as nausea and vomiting, and general factors such as the patient's medical history and personal habits. All subjects completed the interview sheets themselves, after which physicians confirmed the details of the medical history based on the completed interview sheets and recorded the information thus obtained for subsequent analyses. The participating physicians had 3-15 years of experience (mean \pm standard deviation: $7.4 \pm 4.3$ years), and all worked for the department.

In general, a clue to the diagnosis of BPPV is a history of recurrent episodes of rotatory vertigo or a floating sensation precipitated by certain head positions and movements, usually lasting from a few seconds to several minutes. A diagnosis of posterior canal BPPV can be established definitively through the Dix-Hallpike test. ${ }^{16}$ In the present study, patients were judged to be suspicious for BPPV by their medical history of the mentioned features. A definite diagnosis of posterior canal BPPV was made on the basis of the diagnostic criteria described previously. ${ }^{16}$ All patients with a medical history suggesting BPPV underwent the Dix-Hallpike test using Frenzel glasses to determine the presence or absence of characteristic nystagmus with the following features: horizontal-rotatory nystagmus with a latency of 1-2 seconds and attenuation within 10-20 seconds, and induction of vertigo and nystagmus becoming more difficult as the test is repeated. If patients had nystagmus with all of these features, they were judged to have DHT + BPPV, while those without these features were considered to have a negative result (DHT - BPPV). Patients with cervical spine disease or rheumatoid arthritis were excluded from the study because it was considered difficult to perform the required examinations. This study targeted DHT + BPPV only in order to avoid diagnostic ambiguity. When the cause of dizziness was difficult to determine, patients were referred to the relevant specialist department. Patients with missing data were excluded from the relevant analyses.

Using the information obtained from interviews conducted by the physicians, the relation between each piece of information and the final diagnosis was analyzed, then positive and negative likelihood ratios for a diagnosis of DHT + BPPV along with the $95 \%$ confidence interval (CI) were calculated.

Because BPPV is characterized by vertigo with a short duration, information about the duration of symptoms was obtained to clarify whether the dizziness was brief enough to increase the possibility of a diagnosis of DHT + BPPV by asking patients to specify the duration of their symptoms (eg, 30 seconds or 5 minutes). ${ }^{15}$

Then the relation between the duration of dizziness and the presence or absence of DHT + BPPV was examined by receiver operating characteristic (ROC) curve analysis and the duration corresponding to the maximum Youden index was defined as the cut-off point. Patients with a shorter or longer duration of dizziness than the cut-off value thus obtained were classified as being positive or negative, respectively.

To identify useful questions for predicting a diagnosis of DHT + BPPV, binominal logistic regression analysis was conducted using both the step-up and step-down methods. Inclusion and exclusion of variables was determined based on likelihood ratios of $P<0.05$ and $P>0.1$, respectively. Spearman's correlation coefficient analysis of the questions was performed in advance to determine those that should 
be included as variables. If the coefficient exceeded 0.2 , it was considered that there was a correlation between a pair of items, and only one of them was included in the logistic regression analysis.

To test the validity of the model thus obtained for predicting DHT + BPPV, outpatients who presented to the Department with dizziness from May 2007 to April 2008 were studied (the validation set). The medical history was obtained from this set in the same way as for the derivation set.

Based on the regression coefficients obtained with the resulting logistic regression model, variables were weighted. By aggregating the scores for the relevant predictive factors, a predictive score for the diagnosis of DHT + BPPV was calculated. Then ROC curve analysis of the predictive scores was conducted. The model was also applied to all subjects from the derivation and validation sets to test cross validity. When validation was performed, the data on patients with missing values for selected predictors were excluded from analysis.

StatsDirect (v 2.7.7; StatsDirect Ltd, Altrincham, UK) software was employed for calculation of the likelihood ratios and SPSS (v 15.0; SPSS Inc, Chicago, IL) software for the other statistical analyses.

\section{Results}

Among 3901 patients who first presented to the department from July 2005 to May 2007, 156 had the chief complaint of dizziness. Among 1707 patients who first presented to the department from May 2007 to April 2008, 65 had the chief complaint of dizziness. This study included 145/156 and $61 / 65$ patients, respectively, who gave informed consent to participation. The Dix-Hallpike test could be performed in all of these patients. Clinical characteristics of the subjects (derivation set and validation set) and details of the final diagnosis are shown in Table 1. The causes other than BPPV are also shown in Table 1 and categorized as non-BPPV. Only one patient from the validation set had both DHT + BPPV and depression as causes of dizziness. Comparison between the derivation set and the validation set showed a similar distribution of mean age, gender, and final diagnoses.

ROC curve analysis of the relation between the duration of dizziness and the presence or absence of DHT + BPPV revealed that the maximum Youden Index was located at 15 seconds. Therefore, the cut-off value was set at 15 seconds and the question "Was the duration of dizziness $\leq 15$ seconds?" was included in subsequent analyses.

Questions that showed significant positive or negative likelihood ratios for making a diagnosis of DHT + BPPV are shown in Table 2. Spearman's correlation coefficient
Table I Characteristics of the subjects (derivation and validation sets)

\begin{tabular}{|c|c|c|}
\hline & $\begin{array}{l}\text { Derivation set } \\
(\mathrm{N}=145)\end{array}$ & $\begin{array}{l}\text { Validation set } \\
(\mathrm{N}=61)\end{array}$ \\
\hline Mean age, $y \pm S D$ & $45.9 \pm 17.4$ & $48.7 \pm 17.1$ \\
\hline Male, $\mathrm{n}(\%)$ & $49(33.8)$ & $25(4 I)$ \\
\hline \multicolumn{3}{|l|}{ Final diagnosis, $\mathbf{n}(\%)^{\mathrm{a}}$} \\
\hline Peripheral disease & $47(32)$ & $24(39)$ \\
\hline DHT+ BPPV & $12(8.3)$ & $6(10)$ \\
\hline Mean age, $y \pm S D$ & $57.0 \pm 17.6$ & $54.7 \pm 16.3$ \\
\hline Male & $6(50)^{\mathrm{b}}$ & $\mathrm{I}(17)^{\mathrm{b}}$ \\
\hline DHT- BPPV & $30(20.7)$ & $14(23)$ \\
\hline Meniere's disease & $3(2.1)$ & $\mathrm{I}(\mathrm{I} .6)$ \\
\hline Vestibular neuritis & $2(1.4)$ & $3(4.9)$ \\
\hline Psychogenic disorders & $56(39)$ & $18(30)$ \\
\hline Depressive disorder & $24(17)$ & $5(8.2)$ \\
\hline Somatoform disorder & $12(8.3)$ & I (I.6) \\
\hline Adjustment disorder & $6(4.1)$ & $5(8.2)$ \\
\hline Panic disorder & $5(3.4)$ & $2(3.3)$ \\
\hline Anxiety disorder & $3(2.1)$ & $3(4.9)$ \\
\hline Hypochondriasis & $2(1.4)$ & I (I.6) \\
\hline Others ${ }^{c}$ & $4(2.8)$ & I (I.6) \\
\hline Central diseases & $8(5.5)$ & $3(4.9)$ \\
\hline Migraine & $3(2.1)$ & I (I.6) \\
\hline Transient ischemic attack & & $2(3.3)$ \\
\hline Others $^{d}$ & $5(3.4)$ & \\
\hline Others & $19(13)$ & $9(15)$ \\
\hline Orthostatic hypotension & $5(3.4)$ & I (I.6) \\
\hline Combined sensory disorder & $3(2.1)$ & I (I.6) \\
\hline Arrhythmia & $2(1.4)$ & \\
\hline Anemia & $2(1.4)$ & \\
\hline Drug-induced & $2(1.4)$ & \\
\hline Cervical vertigo & $2(1.4)$ & \\
\hline Overwork & $2(1.4)$ & I (I.6) \\
\hline Others ${ }^{\mathrm{e}}$ & I (0.7) & $6(9.8)$ \\
\hline Unknown diagnosis & $15(10)$ & $8(13)$ \\
\hline $\begin{array}{l}\text { Patients requiring consultation } \\
\text { with specialists, } n(\%)\end{array}$ & $56(39)$ & $15(25)$ \\
\hline
\end{tabular}

Notes: The derivation set is a group used for development of the predictive model, and the validation set is a group used for validation of the model. aPercentage of patients in each set; the total exceeds 100\% because a patient had multiple diseases; bercentage of DHT+ BPPV patients in each set; "others" includes the following diseases (n): conversion disorder (I), paranoia (I), acute stress disorder (I), and factitious disorder ( $I)$ in the derivation set; phobia (I) in the validation set; " "others" includes the following diseases ( $n$ ): cerebral infarction (I), acoustic neuroma (I), epilepsy (I), Adie's syndrome (I), and alcoholic cerebellar ataxia (I) in the derivation set; " "others" includes the following diseases: vasovagal reflex (I) in the derivation set; vasovagal reflex (I), sleep apnea syndrome (I), sleep deprivation (I), cytomegalovirus infection (I), dehydration (I) and deconditioning (I) in the validation set.

Abbreviations: SD, standard deviation; BPPV, benign paroxysmal positional vertigo; DHT+, positive Dix-Hallpike test; DHT-, negative Dix-Hallpike test.

analysis revealed that some variables were correlated (with the value of the coefficient exceeding 0.2). For those pairs of variables, the positive likelihood ratios shown in Table 2 were compared, and the variable with the higher value was chosen for inclusion in the subsequent logistic analyses. The following items were identified: "duration of dizziness $\leq 15$ seconds," "onset when turning over in bed," "associated 
Table 2 Performance characteristics of individual items

\begin{tabular}{|c|c|c|c|c|}
\hline & $\begin{array}{l}\text { Sensitivity } \\
(95 \% \mathrm{Cl})\end{array}$ & $\begin{array}{l}\text { Specificity } \\
(95 \% \mathrm{Cl})\end{array}$ & $\begin{array}{l}\text { Positive likelihood ratio } \\
(95 \% \mathrm{Cl})\end{array}$ & $\begin{array}{l}\text { Negative likelihood ratio } \\
(95 \% \mathrm{Cl})\end{array}$ \\
\hline \multicolumn{5}{|l|}{ Temporal factors } \\
\hline Sudden onset & $0.92(0.76-1.00)$ & $0.33(0.25-0.4 I)$ & $1.36(1.33-1.39)$ & $0.26(0.04-1.59)$ \\
\hline Recurrence & $0.83(0.62-1.00)$ & $0.29(0.21-0.37)$ & $1.18(1.13-1.22)$ & $0.57(0.24-1.34)$ \\
\hline Diurnal fluctuation & $0.67(0.40-0.93)$ & $0.50(0.41-0.59)$ & $1.33(1.21-1.47)$ & $0.67(0.47-0.94)$ \\
\hline Duration of dizziness $\leq 15$ seconds & $0.42(0.14-0.70)$ & $0.84(0.78-0.90)$ & $2.64(1.94-3.59)$ & $0.69(0.61-0.78)$ \\
\hline \multicolumn{5}{|l|}{ Features } \\
\hline Spinning sensation (rotation) & $0.92(0.76-1.00)$ & $0.65(0.57-0.73)$ & $2.63(2.52-2.74)$ & $0.13(0.02-0.78)$ \\
\hline \multicolumn{5}{|l|}{ Triggers } \\
\hline Onset when turning over in bed & $0.75(0.51-1.00)$ & $0.77(0.69-0.84)$ & $3.23(2.90-3.58)$ & $0.33(0.20-0.53)$ \\
\hline Onset when standing up & $0.75(0.51-1.00)$ & $0.52(0.44-0.6 \mathrm{I})$ & $1.57(1.46-1.69)$ & $0.48(0.29-0.79)$ \\
\hline Onset when looking up & $0.42(0.14-0.70)$ & $0.77(0.70-0.85)$ & $1.84(1.39-2.44)$ & $0.75(0.67-0.85)$ \\
\hline Onset when looking down & $0.50(0.22-0.78)$ & $0.7 \mid(0.63-0.79)$ & $1.73(1.41-2.11)$ & $0.70(0.59-0.83)$ \\
\hline \multicolumn{5}{|l|}{ Accessory symptoms } \\
\hline Deafness & $0.08(0-0.24)$ & $0.95(0.92-0.99)$ & $1.82(0.22-14.98)$ & $0.96(0.95-0.98)$ \\
\hline Nausea and/or vomiting & $0.67(0.40-0.93)$ & $0.60(0.51-0.68)$ & $1.65(1.49-1.83)$ & $0.56(0.40-0.78)$ \\
\hline Double vision & $0.08(0-0.24)$ & $0.94(0.90-0.98)$ & $1.35(0.18-10.28)$ & $0.98(0.96-0.99)$ \\
\hline Faintness & $0.25(0.01-0.50)$ & $0.82(0.76-0.89)$ & $1.40(0.80-2.45)$ & $0.91(0.86-0.97)$ \\
\hline \multicolumn{5}{|l|}{ General factors } \\
\hline History of diabetes mellitus & $0.08(0-0.24)$ & $0.98(0.95-1.00)$ & $3.69(0.32-42.19)$ & $0.94(0.92-0.95)$ \\
\hline Loss of enjoyment & $0.83(0.62-1.00)$ & $0.35(0.27-0.43)$ & $1.28(1.23-1.33)$ & $0.48(0.20-1.11)$ \\
\hline
\end{tabular}

Abbreviation: $\mathrm{Cl}$, confidence interval.

deafness," "double vision," "feeling of blood draining from the body," "history of diabetes mellitus," and "excessive stress." Using these seven items as independent variables, binominal logistic regression analysis was conducted by the step-up method using likelihood ratios. Of the 145 eligible patients, eleven patients who had missing data were excluded from this analysis. As shown in Table 3, a "duration of dizziness $\leq 15$ seconds" and "onset when turning over in bed" were identified as independent predictors of DHT + BPPV. The chi-square test showed significance $(P<0.01)$, and the goodness of fit of the model was confirmed by the HosmerLemeshow test $(P=0.665)$. A similar analysis conducted by the step-down method using likelihood ratios obtained the same results as those found with the step-up method.

When verification of the validity of the predictive model was performed, four patients with missing information for the abovementioned two predictive factors were excluded from the derivation set for subsequent analyses. Based on the regression coefficients obtained, the scores for the two predictive factors were determined, as shown in Table 3, and predictive scores were calculated for each patient. Using these predictive scores and the presence or absence of a diagnosis of DHT + BPPV, a classification table was produced, and the positive and negative predictive values were calculated for three defined thresholds (Table 4). The performance characteristics of the combination of these predictive factors are shown in Table 5.

\section{Discussion}

The present study revealed that a "duration of dizziness $\leq 15$ seconds" and "onset when turning over in bed" were particularly useful items from the medical history for making or excluding a diagnosis of DHT + BPPV. Affirmative answers to both questions yielded a likelihood ratio of 6.81 for diagnosis of DHT + BPPV, while negative answers to both had a likelihood ratio of 0.19 . Therefore, combination of the two items can enable primary care physicians to predict the probability of DHT + BPPV.

Table 3 Results of binomial logistic regression analysis

\begin{tabular}{|c|c|c|c|c|}
\hline Variable & Regression coefficient & Significant probability & Odds ratio $(95 \% \mathrm{Cl})$ & Point* \\
\hline Duration of dizziness $\leq 15$ seconds & 1.47 & 0.028 & $4.36(1.18-16.19)$ & I \\
\hline Onset when turning over in bed & 2.32 & 0.001 & $10.17(2.49-41.63)$ & 2 \\
\hline Constant & -4.05 & $<0.001$ & & \\
\hline
\end{tabular}

Notes: Model chi-square test, $P<0.01$. Predictive value $=91.0 \%$. Calculated based on regression coefficients.

Abbreviation: $\mathrm{Cl}$, confidence interval. 
Table 4 Performance of the BPPV prediction model

\begin{tabular}{|c|c|c|c|c|}
\hline & \multicolumn{4}{|c|}{$\begin{array}{l}\text { Number of appropriate items } \\
\text { (prediction score) }\end{array}$} \\
\hline & 0 & I & 2 & 3 \\
\hline \multicolumn{5}{|c|}{ Derivation set $(\mathrm{N}=|4|), \mathrm{n}(\%)$} \\
\hline $\mathrm{DHT}+\mathrm{BPPV}$ & $I(I)$ & $2(8)$ & $4(15)$ & $5(42)$ \\
\hline Others* & $75(99)$ & $24(92)$ & $23(85)$ & $7(58)$ \\
\hline \multicolumn{5}{|c|}{ Validation set $(\mathrm{N}=6 \mathrm{I}), \mathrm{n}(\%)$} \\
\hline $\mathrm{DHT}+\mathrm{BPPV}$ & I (3) & $0(0)$ & $2(13)$ & $3(38)$ \\
\hline Others* & $30(97)$ & $7(100)$ & $13(87)$ & $5(63)$ \\
\hline
\end{tabular}

Notes: With a threshold of 0.5 , the positive predictive value (PPV) and negative predictive value (NPV) for the derivation set were $16.9 \%$ and $98.7 \%$, respectively, and those for the validation set were $16.7 \%$ and $96.8 \%$, respectively. With a threshold of 1.5, PPV and NPV for the derivation set were $23.1 \%$ and $97.1 \%$, respectively, and those for the validation set were $21.7 \%$ and $97.4 \%$, respectively. With a threshold of 2.5, PPV and NPV for the derivation set were $41.7 \%$ and $94.6 \%$, respectively, and those for the validation set were $37.5 \%$ and $94.3 \%$, respectively. *Others include DHT - BPPV and non-BPPV.

Abbreviations: BPPV, benign paroxysmal positional vertigo; $\mathrm{DHT}+$, positive DixHallpike test; DHT-, negative Dix-Hallpike test.

When the two predictive items were compared, it was found that the odds ratio for "onset when turning over in bed" was 10.17 , which made it the most useful interview item for predicting a diagnosis of DHT + BPPV. Previous studies have also suggested that "onset when turning over in bed" is a useful item in patient medical history for making a diagnosis of BPPV, while the present study demonstrated that this is the most distinctive symptom of DHT + BPPV. ${ }^{1,16,19-22}$ In the authors' experience, dizziness can be exacerbated by body movement in many diseases. However, turning over in bed involves movement of the head and body without affecting blood pressure, so dizziness may not worsen in patients with other common diseases such as orthostatic hypotension and psychogenic disorders. This may be why the effect of turning over in bed had a high specificity for making a diagnosis of BPPV. Although turning over in bed can occur at any time while sleeping, patients with BPPV may become habituated to their symptoms so that is most likely to be noticed at the time of awakening in the

Table 5 Performance characteristics of the two predictive items* for DHT + BPPV in the combined derivation and validation sets

\begin{tabular}{llll}
\hline & Sensitivity & Specificity & LR \\
\hline $\begin{array}{l}\text { Positivity } \\
\text { of both }\end{array}$ & $0.44(0.21-0.67)$ & $0.93(0.90-0.97)$ & $6.8 \mathrm{I}(5 . \mathrm{II}-9.10)$ \\
$\begin{array}{l}\text { Positivity } \\
\text { of only one }\end{array}$ & $0.44(0.2 \mathrm{I}-0.67)$ & $0.64(0.57-0.7 \mathrm{I})$ & $\mathrm{I} .22(\mathrm{I} .05-1.43)$ \\
$\begin{array}{l}\text { Positivity } \\
\text { of none }\end{array}$ & $0.1 \mathrm{I}(0-0.26)$ & $0.43(0.36-0.50)$ & $0.19(0.08-0.47)$ \\
\hline
\end{tabular}

Note: *These are "duration of dizziness $\leq 15$ seconds" and "onset when turning over in bed."

Abbreviations: BPPV, benign paroxysmal positional vertigo; DHT+, positive DixHallpike test; LR, likelihood ratio. early morning. This is supported by previous reports suggesting that peripheral dizziness can be suspected in patients who have symptoms at this time. ${ }^{23,24}$

The duration of dizziness was also a predictive factor. In previous studies, factors such as the mode of onset and the duration of episodes were found to be important for the diagnosis and treatment of causes of dizziness. ${ }^{1,2,15}$ The present study revealed that the duration of dizziness is particularly important for making or excluding a diagnosis of BPPV. While it has been reported that the duration of dizziness in patients with BPPV is $\leq 1$ minute, a review of BPPV that regarded the Dix-Hallpike test as important has suggested that the typical duration of dizziness is only $10-20$ seconds, which is consistent with the results of the present study. ${ }^{1,16}$

Apart from the above two items, significant positive and negative likelihood ratios were confirmed for items such as "diurnal fluctuation," "spinning sensation," "onset when standing up, looking up, or looking down," and "associated nausea or vomiting." "Diurnal fluctuation" may be a useful item for detecting BPPV because the symptoms of patients with other diseases improve or worsen over the long-term due to changes of the underlying condition, so the expression "diurnal fluctuation" (which means improvement or exacerbation in a short period) would not be used by patients with BPPV. Consequently, "diurnal fluctuation" becomes a useful item in the medical history for making or excluding a diagnosis of BPPV. It is also known that a "spinning sensation" (ie, rotatory vertigo) generally suggests the presence of peripheral vertigo. Moreover, rotatory vertigo with nausea and vomiting is considered to have a strong association with peripheral vertigo. ${ }^{1,20}$

It is known that the pattern of symptoms, the duration of dizziness, and the triggers are particularly important to determine when taking a history. The present study demonstrated that two simple items from the history could be used for predicting a diagnosis of DHT + BPPV, which should be beneficial for improving the diagnosis of causes of dizziness.

\section{Limitations}

This study was performed at the department of general medicine of a university hospital and it remains unclear whether the results are applicable to community hospitals and local clinics. This study targeted BPPV of the posterior canals with DHT + only. Therefore, further analysis is needed to clarify whether the results of the present study can be applied to all BPPV cases. 


\section{Conclusion}

A "duration of dizziness $\leq 15$ seconds" and "onset when turning over in bed" are the two most important questions among various historical features of BPPV.

\section{Disclosure}

This study was funded by a Health and Labour Sciences Research Grant 2004 (Health Technology Assessment Research). Grant Number: H16-Iryou-Ippan-025. Recipient: Masatomi Ikusaka. The authors declare that there are no other conflicts of interest associated with the present study.

\section{References}

1. Derebery MJ. The diagnosis and treatment of dizziness. Med Clin North Am. 1999;83(1):163-177.

2. Hoffman RM, Einstadter D, Kroenke K. Evaluating dizziness. Am J Med. 1999;107(5):468-478.

3. Hanley K, O'Dowd T. Symptoms of vertigo in general practice: a prospective study of diagnosis. Br J Gen Pract. 2002;52(483): 809-812.

4. Nedzelski JM, Barber HO, McIlmoyl L. Diagnoses in a dizziness unit. J Otolaryngol. 1986;15(2):101-104.

5. Kroenke K, Hoffman RM, Einstadter D. How common are various causes of dizziness? A critical review. South Med J. 2000;93(2):160-167.

6. Drachman DA, Hart CW. An approach to the dizzy patient. Neurology. 1972;22(4):323-334.

7. Katsarkas A. Benign paroxysmal positional vertigo (BPPV): idiopathic versus post-traumatic. Acta Otolaryngol. 1999;119(7):745-749.

8. Sekine K, Sato G, Takeda N. Incidence of vertigo and dizziness disorders at a university hospital. Nihon Jibiinkoka Gakkai Kaiho. 2005;108(9):842-849. Japanese.

9. De la Meilleure G, Dhaene I, Depondt M, Damman W, Crevits L, Vanhooren G. Benign paroxysmal positional vertigo of the horizontal canal. J Neurol Neurosurg Psychiatry. 1996;60:68-71.
10. Cakir BO, Ercan I, Cakir ZA, Civelek S, Sayin I, Turgut S. What is the true incidence of horizontal semicircular canal benign paroxysmal positional vertigo? Otolaryngol Head Neck Surg. 2006;134(3):451-454.

11. Hornibrook J. Horizontal canal benign positional vertigo. Ann Otol Rhinol Laryngol. 2004;113(9):721-725.

12. Moon SY, Kim JS, Kim BK, et al. Clinical characteristics of benign paroxysmal positional vertigo in Korea: a multicenter study. $J$ Korean Med Sci. 2006;21(3):539-543.

13. Parnes LS, Agrawal SK, Atlas J. Diagnosis and management of benign paroxysmal positional vertigo (BPPV). CMAJ. 2003;169(7):681-693.

14. Lee SH, Kim JS. Benign paroxysmal positional vertigo. J Clin Neurol. 2010;6(2):51-63.

15. Hotson JR, Baloh RW. Acute vestibular syndrome. N Engl J Med. 1998; 339(10):680-685.

16. Furman JM, Cass SP. Benign paroxysmal positional vertigo. $N$ Engl $J$ Med. 1999;341(21):1590-1596.

17. Tirelli G, D'Orlando E, Giacomarra V, Russolo M. Benign positional vertigo without detectable nystagmus. Laryngoscope. 2001;111(6): 1053-1056.

18. Balatsouras DG, Korres SG. Subjective benign paroxysmal positional vertigo. Otolaryngol Head Neck Surg. Epub October 13, 2011.

19. Froehling DA, Silverstein MD, Mohr DN, Beatty CW, Offord KP, Ballard DJ. Benign positional vertigo: Incidence and prognosis in a population-based study in Olmsted county, Minnesota. Mayo Clin Proc. 1991;66(6):596-601.

20. Hanley K, O'Dowd T, Considine N. A systematic review of vertigo in primary care. Br J Gen Pract. 2001;51(469):666-671.

21. Baloh RW, Honrubia V, Jacobson K. Benign positional vertigo: clinical and oculographic features in 240 cases. Neurology. 1987;37(3): 371-378.

22. Dix MR, Hallpike CS. The pathology symptomatology and diagnosis of certain common disorders of the vestibular system. Proc R Soc Med. 1952;45(6):341-354.

23. Fisher CM. Vertigo in cerebrovascular disease. Arch Otolaryngol. 1967; 85(5):529-534

24. Berkowitz BW. Matutinal vertigo. Clinical characteristics and possible management. Arch Neurol. 1985;42(9):874-877.
International Journal of General Medicine

\section{Publish your work in this journal}

The International Journal of General Medicine is an international, peer-reviewed open-access journal that focuses on general and internal medicine, pathogenesis, epidemiology, diagnosis, monitoring and treatment protocols. The journal is characterized by the rapid reporting of reviews, original research and clinical studies across all disease areas.

\section{Dovepress}

A key focus is the elucidation of disease processes and management protocols resulting in improved outcomes for the patient.The manuscript management system is completely online and includes a very quick and fair peer-review system. Visit http://www.dovepress.com/ testimonials.php to read real quotes from published authors. 